\title{
O TEATRO COMO INSTRUMENTO PEDAGÓGICO NA EDUCAÇÃO DE SURDOS
}

\author{
THEATRE AS EDUCATIONAL TOOL IN EDUCATION OF DEAF PEOPLE \\ TEATRO COMO HERRAMIENTA EDUCATIVA EN LA EDUCACIÓN DE \\ PERSONAS SORDAS
}

\author{
Divino Gomes Vieira* \\ Hildomar José de Lima **
}

\begin{abstract}
Resumo
Por ser uma arte de caráter fortemente visual, que aglutina todas as outras artes e linguagens, o teatro tem grande receptividade nas comunidades surdas e pode ser uma proposta pedagógica eficiente para melhorar o desempenho de alunos surdos e tornar sua educação mais interessante e significativa. O objetivo deste trabalho é trazer reflexões sobre os benefícios do uso do teatro na educação do surdo. A experiência dramática, levada à sala de aula, auxilia o desenvolvimento cognitivo e pode ser avaliada como um percurso, por meio do qual ocorre a transformação da interioridade do aluno surdo e também de sua realidade exterior. Para o desenvolvimento deste trabalho, foram essenciais as obras de Courtney e Reverbel, no que diz respeito ao teatro e à educação, assim como os textos de Freitas, que desenvolveu pesquisas sobre o teatro e a educação de surdos, apontando a importância das atividades de dramatização teatral, propostas em salas de aula, para motivar as práticas de linguagem escrita em Língua Portuguesa do aluno surdo e a redução dos entraves linguísticos entre surdos e ouvintes.
\end{abstract}

Palavras-chave: teatro, educação de surdos, inclusão.

Atuar dramaticamente é uma aptidão que faz parte da essência do ser humano e se inicia na primeira infância, a partir das fases iniciais do desenvolvimento infantil, quando o choro, os gritos e os movimentos do corpo respondem às sensações físicas de fome, frio e dor. Essas são as primeiras formas de expressão e comunicação das crianças com o ambiente no qual iniciarão sua jornada como participantes do grande drama da vida. À medida que a criança se desenvolve, suas habilidades dramáticas vão se ampliando, conquistando o domínio da expressão facial, da linguagem gestual e da comunicação oral.

\footnotetext{
* Mestrando em Estudos Linguísticos pelo Programa de Pós-Graduação em Letras e Linguística a Universidade Federal de Goiás-UFG. E-mail: divinogoviteatro@hotmail.com

** Doutorando em Estudos Linguísticos pelo Programa de Pós-Graduação em Letras e Linguística a Universidade Federal de Goiás; Professor do Departamento de Libras e Tradução da Faculdade de Letras da Universidade Federal de Goiás- UFG. E-mail: hildomarlima@gmail.com
} 
De acordo com Richard Courtney, a habilidade dramática da criança, em seus primeiros anos de vida, é essencial para o seu desenvolvimento cognitivo e motor. Quando ela "passa a jogar, desenvolve o seu humor, finge ser ela mesma ou outro alguém. [...] Fingir ser outra pessoa - atuar - é parte do processo de viver” (2003, p.3). Essa habilidade para perceber uma situação, suas possibilidades cômicas ou dramáticas e as ações que envolvem o 'faz de conta', é uma das mais peculiares características do ser humano.

$\mathrm{Na}$ idade adulta, essas duas linguagens, a corporal e a oral, tornam-se automatizadas, obedecendo inconscientemente ao comando de um pensamento, um sentimento ou emoção do cotidiano. A par dessa forma instintiva de dramatizar, o homem criou e desenvolveu meios de traduzir e dar significado ao pensamento através de uma dramatização planejada: a representação teatral, onde os tons de voz, os gestos, o deslocar-se no espaço cênico e os movimentos do corpo, são conscientemente delineados, visando alcançar um determinado efeito ou significado visual, com o objetivo de provocar empatia no espectador.

Em uma obra voltada ao teatro na educação, Olga Reverbel observa que as nossas escolas, por considerarem prioridade os aspectos cognitivos da educação, investem pouco nos “aspectos afetivos e psicomotores”, embora a maioria das obras dedicadas à educação infantil aponte sua importância no desenvolvimento da criança. Essa autora ressalta a importância das “atividades de expressão", levadas aos alunos como parte do "jogo teatral” (1989, p. 34). E é assim, jogando — também poderíamos dizer: "brincando" — , que o aluno vai além do mundo exterior e descobre seu mundo interior. Do encontro desses dois mundos "nasce a expressão", lembra Reverbel (1989, p. 38).

Imprescindível a uma boa formação, o teatro é de grande funcionalidade, quando utilizado na educação de alunos surdos. A linguagem universal do teatro estimula a aprendizagem, potencializando o raciocínio cognitivo, a capacidade comunicativa e a compreensão de mundo. Por ser uma arte plural, de caráter fortemente visual, que aglutina todas as artes e linguagens, o teatro tem grande receptividade nas comunidades surdas. $\mathrm{O}$ objetivo deste trabalho, portanto, é trazer reflexões sobre o teatro como um horizonte de possibilidades para a educação de surdos, uma via canalizadora do seu potencial artístico corporal, considerando a experiência dramática como um processo de desenvolvimento cognitivo, um percurso, por meio do qual ocorrem transformações da interioridade surda e de sua realidade exterior. 
Para o desenvolvimento deste trabalho, foram essenciais as obras de Richard Courtney (2003) e Olga Reverbel (1989), no que diz respeito ao teatro e à educação, assim como o texto de Cilene Freitas (2014), que aborda questões sobre o teatro e a educação de surdos, apontando a importância das atividades de dramatização em sala de aula, para aumentar a motivação do aluno surdo, tanto nas práticas de escrita em Língua Portuguesa, quanto na assimilação de outras disciplinas, atuando ainda na redução dos entraves linguísticos entre surdos e ouvintes.

\section{Teatro de surdos no Brasil}

Nos últimos anos, no Brasil, o teatro surdo vem crescendo com a formação de novos grupos, que surgem no rastro de grupos mais antigos, como o Signatores, o TBS, o grupo Libração e a companhia Quase9 teatro. Por terem desenvolvido um trabalho constante e de qualidade, esses grupos se tornaram referenciais. O grupo Signatores, formado em 2010, em Porto Alegre, tem como proposta, segundo o site oficial do grupo, "investigar as possibilidades de criação artísticas dos surdos, incentivar a formação de docentes e pesquisadores na área teatral, aproximar jovens e adultos surdos das artes cênicas" (GRUPO SIGNATORES, 2015). O TBS - Teatro Brasileiro de Surdos, criado no Rio de Janeiro, em 2005, por profissionais surdos e ouvintes, é formado por atores e bailarinos surdos. O grupo, que está voltado para pesquisas ligadas à cultura popular brasileira, pesquisa diferentes linguagens e adaptam contos populares à cultura surda. Segundo publicação em seu site oficial, o TBS “investe nas infinitas possibilidades que os surdos têm de apresentar sua arte, utilizando sua língua e o corpo como via de expressão" (TBS BRASIL, 2015). O grupo Libração, de Joinvile, tem como proposta um teatro de improviso, denominado Playback, e seu objetivo, segundo o site oficial do grupo, é dar vez e "voz" a todos os surdos, principalmente as vozes que nem sempre têm a oportunidade se manifestar e serem ouvidas. Outro grupo de muita expressão é a Companhia Quase9 Teatro, formado em 2008 por exalunos da Unicamp. Trabalhando com a proposta do teatro físico, o grupo mistura dança e teatro para traduzir o universo dos surdos.

Além do trabalho desses grupos, algumas ONGs, de acordo com Freitas (2014), ministram aulas de teatro e dança para surdos. Uma das ONGs que se destacam nesse trabalho é a Associação Velazquez de Assistência ao Surdo - AVAS, do Rio de Janeiro. Essas iniciativas, contudo, são pouco conhecidas e o trabalho teatral do surdo raramente é divulgado 
nas mídias. De qualquer forma, as ações desenvolvidas no universo do teatro surdo, assim como no teatro utilizado como forma de educação, inclusão, integração e interação social, são positivamente significativas.

\section{Teatro e educação de surdos}

O teatro está intimamente ligado à história do pensamento educacional. Richard Courtney aponta a necessidade de "uma educação que habilite os homens para desenvolverem suas qualidades humanas" (2003, p. 3). Essa é uma necessidade percebida por diversos pensadores, em diferentes épocas, e se tornou um dos mais importantes imperativos educacionais do nosso tempo. O teatro, por sua capacidade de absorção de linguagens e culturas, por seu poder de produzir encantamento, ao representar a realidade, mostra-se capaz de romper fronteiras, possibilitando uma visão educacional mais humanizada, aberta à diversidade.

Na Antiguidade, a Grécia, berço do teatro ocidental, foi um exemplo da importância da arte dramática na formação de seus jovens. A dança, a música e os esportes faziam parte das atividades que deviam ser aprendidas pelos alunos, juntamente com leitura, escrita e declamação das obras de seus poetas, especialmente Homero e Hesíodo. As leituras eram praticadas com o uso de recursos teatrais, como inflexão de voz, expressão facial e gestos dramáticos. Courtney também observa o valor dado pelos antigos gregos à dança, arte que "recebia especial ênfase na medida em que era fundamental a todas as religiões e cerimônias dramáticas; sua forma era intensamente dramática e exigia grande habilidade" (2003, p. 5).

Os recursos oferecidos pelo teatro sempre foram utilizados por educadores. Na Idade Média, peças religiosas, geralmente escritas por monges, eram encenadas nos mosteiros da Europa. Com a expansão marítima, esses autos religiosos também foram usados no trabalho de catequização dos povos autóctones, em terras colonizadas por portugueses e espanhóis. Nos séculos seguintes, os recursos pedagógicos da arte teatral continuaram a ser buscados por educadores e encontraram um lugar de destaque na educação moderna. A Escola Nova, proposta por Jean Piaget (1896-1980), ao rejeitar os sistemas educacionais que levavam a criança a se acomodar aos conhecimentos tradicionais, incentivou a inventividade e as atitudes críticas, sugerindo as artes como forma de desenvolvimento dessas potencialidades. Desde então, o teatro vem sendo utilizado como estratégia para o desenvolvimento da 
criatividade e da capacidade crítica da criança e do adolescente nos mais diversos contextos educacionais.

O teatro pode ser compreendido como um recurso valioso na educação do aluno surdo, pois a língua de sinais, por suas características visuoespaciais, apresenta afinidades com a gestualidade teatral. Como estratégia de ensino e aprendizagem, o teatro facilita a abordagem de conteúdos e conceitos, permitindo ao surdo uma melhor compreensão de seu objeto de estudo, considerando a possibilidade de se expressar artisticamente, sem utilizar a língua dos ouvintes.

Quando se retoma a história da educação dos surdos, uma referência indispensável é ao abade francês Charles Michel de L’Epée, um dos primeiros educadores de surdos. Como religioso católico, L’Epée se mostrava preocupado com a salvação das almas dos surdos que viviam sem conhecer a palavra de Deus, sem o catecismo e sem a confissão. Ao observar a língua de sinais utilizada pelos surdos dos subúrbios de Paris, o abade L’Epée viu naquela forma de comunicação "desconhecida pela sociedade, a grande esperança dos surdos se comunicarem e aprendeu também a utilizá-la" (FREITAS, 2014, p. 65). Essa iniciativa fez com que L’Epée entrasse para a História como o primeiro ouvinte a utilizar a forma natural de comunicação dos surdos: a língua de sinais.

O método pedagógico de L’Epée valorizava o uso de gestos e de todos os sinais usados na comunidade dos surdos. $\mathrm{O}$ abade acreditava na possibilidade de ensinar aos seus alunos surdos, por meio da visão, tudo aquilo que era ensinado às crianças ouvintes por meio da audição. Antes dos esforços de L'Epée, os surdos não compartilhavam de direitos sociais essenciais, pois eram considerados desprovidos de inteligência. Sem instrução e incapazes de se comunicar com outros homens, eram proibidos de receber a comunhão, de se casar e de receber heranças. Com o desenvolvimento da Língua de Sinais iniciou-se, segundo Freitas (2014), o processo de reconhecimento dos surdos como cidadãos inteligentes, dignos de serem educados e de ingressarem no mercado de trabalho.

No Rio de janeiro, em 1857, o Imperador Pedro II, que tinha um filho surdo, fundou o Instituto Nacional de Surdos-Mudos, atual Instituto Nacional de Educação de Surdos (INES), reconhecido como centro nacional de referência na área de Surdez (Goldfeld, 2002). Segundo Freitas, o INES tinha como princípio, inicialmente, "valorizar a participação da família na escolha da forma de comunicação [...] utilizada, permitindo assim, uma partilha de ideias, sentimentos e informações" (2014, p. 71). Com isso, a Língua Brasileira de Sinais (Libras) se 
fortaleceu como meio de comunicação e expressão do surdo e foi legalmente reconhecida pela lei 10.436 (BRASIL, 2002) e regulamentada pelo decreto 5.626 (BRASIL, 2005).

Nos últimos anos, com o aumento do número de estudiosos dedicados a pesquisas sobre a educação de surdos, as instituições de ensino buscam se adequar às distintas realidades apresentadas, visando atender às necessidades de seus alunos surdos no que se refere ao seu desenvolvimento cognitivo, educacional, cultural e social. Considerando-se esse contexto, o teatro é sugerido como estratégia viável no processo de ensino e de aprendizagem desses alunos por duas razões especiais. Em primeiro lugar, pelo fato de proporcionar melhor convivência entre surdos e ouvintes, ao romper algumas barreiras na comunicação. Em segundo, por motivar os alunos surdos a participarem mais ativamente de práticas de leitura e escrita em Língua Portuguesa.

Por ser uma atividade quase sempre realizada em grupo, a arte dramática possibilita a troca de experiências, informações e vivências cotidianas, dentro e fora da sala de aula, enriquecendo a aprendizagem e o convívio entre esses dois grupos linguísticos. No que se refere às inter-relações no contexto educacional, o teatro consegue proporcionar convívio mais efetivo e global entre surdos e ouvintes. Nesse contexto, o professor deve se colocar como mediador, oportunizando aos seus alunos a construção de um aprendizado mais significativo, por meio de atividades que exploram a expressão corporal. Para Freitas, “a linguagem teatral pode ser um grande diferencial no estudo sobre a diversidade e na inclusão de pessoas surdas na sociedade, favorecendo de forma significativa a comunicação entre surdos e ouvintes" (2014, p. 18).

De acordo com Teresa Cristina Rude e Paula Guerchon (2002, p. 23), no espaço do teatro o aluno se sente estimulado a liberar sua imaginação, expor suas ideias, se revelar criativamente e se expressar corporalmente, mostrando habilidades em lidar com a linguagem oral e não oral:

[...] seja no ato de ouvir histórias ou contar, seu corpo vai criando formas e sons, e a comunicação vai se dando com total liberdade de expressão. É uma atividade dinâmica, Lúdica e expressiva que enfoca o corporal, sensorial e emocional, englobando formas de comunicação e expressão através do corpo, do desenho, da língua de sinais, da linguagem oral e escrita, na busca incessante das diversas formas escritas para contar e viver suas próprias histórias.

O teatro permite a expressão de sentimentos, independentemente do canal comunicativo de que se utiliza, tornando-se assim uma arte naturalmente inclusiva. Com 
relação à prática da linguagem escrita, os surdos apresentam grandes dificuldades na compreensão e produção de textos escritos em Língua Portuguesa, mesmo depois de frequentar escolas por um bom tempo (Guarinello, 2007). Nas diversas situações de representação, pensadas para o contexto de uma sala de aula, o aluno surdo terá a oportunidade de trazer as diversas experiências linguísticas cotidianas para o ambiente escolar e rediscutir, por exemplo, algumas convenções sociais, ressignificando o papel da escrita em sua vida.

No quadro de disciplinas da educação básica, há competências que permitem um aprendizado com maior apelo artístico e cultural, tal como ocorre no ensino de Língua Portuguesa, Literatura e Artes. Essas disciplinas podem integrar o surdo a um leque de atividades artísticas, colocando-o em contato com diferentes textos escritos. Nesse sentido, o teatro representa uma proposta pedagógica, que oportuniza transformar o que está em escrito em cena dramática. Os Parâmetros Curriculares Nacionais para o Ensino Médio (2002), ou $\mathrm{PCN}+$, referem-se a uma discussão da contemporaneidade,

[...] segundo a qual a arte é considerada um conhecimento humano articulado no âmbito da sensibilidade, da percepção e da cognição. Por meio da arte [...] é possível revelarem-se significados, modos de criação e comunicação sobre o mundo da natureza e da cultura (BRASIL, 2002, p. 179-180).

Surdos e ouvintes pertencem a culturas distintas, as quais configuram o modo de ser de cada grupo. Os surdos pertencem "a um mundo de experiências visuais", que se diferencia do mundo dos ouvintes, constituído em grande parte por símbolos auditivos (Perlin, 1998, p. 56). Nesse sentido, o teatro se constitui como instrumento pedagógico eficaz na educação de surdos, especialmente no que se refere ao processo de apropriação de conhecimentos e de bens culturais.

Os PCN+, ao explicitarem os três conjuntos de competências e habilidades que deveriam ser alcançadas pelo aluno — ou seja, "comunicar e representar", "investigar e compreender" e "contextualizar social ou historicamente os conhecimentos" —, abrem espaço para a inclusão do teatro na educação de surdos e ouvintes. Com suas peculiaridades, o teatro vem contribuindo positivamente para a formação e a educação do aluno surdo, auxiliando o desenvolvimento das competências e habilidades apontadas nesse documento, e aumentando também nos grupos o espírito de colaboração e solidariedade. Freitas (2014, p. 85) destaca que, no teatro com surdos, 
[...] os jogos contribuem para um trabalho interativo, com surdos e ouvintes, onde cada um trabalha para alcançar seus objetivos, como atores e observadores, mas experimentando ações em conjunto e vivenciando experiências que transporão para a vida diária. Os jogos permitem também a exploração de técnicas teatrais que facilitam a comunicação do surdo com a plateia ouvinte, resultante da criatividade e improvisação.

Dessa forma, surdo e ouvinte são levados a ter contato com as mais diversas formas de criações artísticas as quais estarão, de uma forma ou de outra, ligadas à convivência entre pessoas e também ao registro escrito de fatos, normas e orientações. De acordo com o PCN+, "conhecer arte é produzir, interpretar, formas artísticas e culturais em uma dimensão crítica e contextualizada, segundo os sistemas simbólicos que integram cada linguagem própria da arte" (2002, p. 180). O ecletismo artístico do teatro contribui de forma efetiva para o aprendizado global do aluno. A dramatização torna um enredo, uma história ou mesmo um poema mais compreensível, possibilitando uma construção coletiva de significados. Os alunos se vêm diante da situação de atores e coautores do próprio aprendizado, mediados pelo professor. Os resultados se apresentam na forma de obtenção de experiências, conhecimento mais aprofundado dos conteúdos curriculares, ou seja, uma aprendizagem mais eficaz tanto para o surdo quanto para o ouvinte.

\section{Considerações finais}

A escola, como espaço de ensino aprendizagem, tem papel decisivo na formação do surdo e suas práticas precisam alinhar-se ao objetivo de incluir esse aluno no contexto educacional. Segundo Freitas (2014), o Projeto Político Pedagógico da escola deve prever a promoção da inclusão dos surdos, enquanto sujeitos culturais, buscando amenizar os obstáculos de comunicação entre surdos e ouvintes, favorecendo, de forma significativa, a comunicação, a interação e a convivência com as diferenças, tendo o teatro, com suas múltiplas possibilidades, como instrumental pedagógico.

Atualmente as escolas, em suas salas de aulas, estão abrindo mais espaços para a educação de todos. Com isso, o surdo vem conquistando seu espaço de direito na educação e começa a obter resultados mais positivos. Nas salas de aulas com alunos surdos, é possível observar como a dramaturgia ameniza, substancialmente, os impactos das barreiras comunicativas entre surdos e ouvintes, oportunizando uma melhor qualidade nas relações entre esses grupos linguísticos. A arte teatral, ao trazer motivações para as práticas de 
linguagem escrita, propicia melhor desenvolvimento cognitivo, aguçamento do senso crítico e perceptíveis melhoras na vida escolar e na formação global do aluno surdo.

\begin{abstract}
Because it is a strongly visual character of art, which brings together all the other arts and languages, the theater has great receptivity on deaf communities and can be an effective pedagogical approach to improve the performance of deaf students and make her more interesting and meaningful education. The objective of this work is to bring reflections on the benefits of theater use in deaf education. The dramatic experience brought to the classroom aids cognitive development and can be evaluated as a route through which occurs the transformation of the deaf interiority and also your outer reality. To develop this work, it was essential works of Courtney and Reverbel, with regard to the theater and education, as well as the texts of Freitas, author who have developed research on theater and education of the deaf, pointing out the importance of theatrical dramatization activities proposed in classrooms to motivate language practices written in Portuguese language, the deaf student, and the reduction of language barriers between deaf and hearing.
\end{abstract}

Keywords: theater, deaf education, inclusion.

\title{
Resumen
}

Debido a que es un carácter fuertemente visual del arte, que reúne a todas las otras artes e idiomas, el teatro tiene gran receptividad en las comunidades sordas y puede ser un enfoque pedagógico eficaz para mejorar el rendimiento de los estudiantes sordos y hacerla más interesante y educación significativa. El objetivo de este trabajo es llevar a reflexiones sobre los beneficios del uso del teatro en la educación de los sordos. La experiencia dramática traído al aula ayuda a desarrollo cognitivo y se puede evaluar como una ruta a través del cual se produce la transformación de la interioridad sordos y también su realidad externa. Para desarrollar este trabajo, era obras esenciales de Courtney y Reverbel, en relación con el teatro y la educación, así como los textos Freitas, que se desarrolló la investigación sobre el teatro y la educación de los sordos, señalando la importancia de las actividades de dramatización teatral, propuesta en los salones de clase para motivar a las prácticas del lenguaje escrito en lengua portuguesa, el estudiante sordo, y la reducción de las barreras del idioma entre sordos y oyentes.

Palabras clave: teatro, educación sorda, de inclusión.

\section{Referências}

BRASIL. Lei 10.436, de 24 de abril de 2002. Diário Oficial da União - publicado em 25 de abril de 2002; $181^{\circ}$ da Independência e $114^{\circ}$ da República. Brasília, DF: Senado, 2002. Disponível em: <http://www.planalto.gov.br/ccivil/leis/2002/L10436.htm>. Acesso em: 01 dez. 2015.

BRASIL. Parâmetros Curriculares para o Ensino Médio: linguagens, códigos e suas tecnologias. Orientações educacionais complementares aos Parâmetros Curriculares Nacionais. Brasília: MEC/SEB, 2002. 
BRASIL. Decreto 5.626, de 22 de dezembro de 2005. Diário Oficial da União - publicado em 23 de dezembro de 2005; $184^{\circ}$ da Independência e $117^{\circ}$ da República. Brasília, DF: Senado, 2005. Disponível em: <http://www.planalto.gov.br/ccivil/_Ato2004-2006/2005/Decreto/ D5626.htm>. Acesso em: $01 \mathrm{dez} .2015$.

COURTNEY, Richard. Jogo, teatro e pensamento. São Paulo: Perspectiva, 2003 (Col. Estudos).

FREITAS, Cilene Rodrigues Carneiro. Processo de compreensão e reflexão sobre iniciação teatral de surdos. 2014. 154 f. Texto base Dissertação (mestrado) - Universidade de Brasília, DF. Disponível em:

$<$ http://repositorio.unb.br/06/1/2014_CileneRodriguesCarneiroFreitas.pdf $>$. Acesso em 08 nov. 2015.

GOLDFELD, M. A criança surda: linguagem e cognição numa perspectiva sociointeracionista. 3. ed. São Paulo: Plexus, 2002.

GRUPO SIGNATORES. Dica de Leitura. Disponível em: http://www.signatores.com.br/> Acesso em: 16 nov. 2015

GUARINELLO, A. C. O papel do outro na escrita de sujeitos surdos. São Paulo: Plexus, 2007.

PERLIN, G. Identidades Surdas. In: SKLIAR, C. (Org.) A Surdez: um olhar sobre as diferenças. Porto Alegre: Editora Mediação, 1998.

QUASE9TEATRO. Disponível em: https://www.facebook.com/quase9teatro. Acesso em: 23 out. 2015

REVERBEL, Olga. Jogos teatrais na escola:atividades globais de expressão. São Paulo: Scipione, 1989.

RUDE, Teresa Cristina S.; GUERCHON, Paula. Teatro para Surdos: Uma abordagem de comunicação e expressão do não verbal ao verbal. Revista Arqueiro - Instituto Nacional de Educação de Surdos, Rio de Janeiro, vol. 6, dez. 2002. Disponível em: http://www.ines.gov.br/publicacoes/revista-arqueiro/arqueiro_06.pdf Acesso em: 23 de Nov. 2015

TBS BRASIL. Teatro Brasileiro de Surdos. Disponível em: http://tbsbrasil.blogspot.com.br/ Acesso em: 12 nov. 2015. 